ARTICLE

\title{
Towards a greater global understanding of wellbeing: A proposal for a more inclusive measure
}

\author{
Louise Lambert - Tim Lomas - Margot P van de Weijer - Holli Anne Passmore - Mohsen \\ Joshanloo - Jim Harter - Yoshiki Ishikawa · Alden Lai - Takuya Kitagawa - Dominique \\ Chen · Takafumi Kawakami · Hiroaki Miyata · Ed Diener
}

\begin{abstract}
The science of wellbeing has come a long way from the early days of measuring wellbeing via a nation's GDP, and wellbeing measures and concepts continue to proliferate to capture its various elements. Yet, much of this activity has reflected concepts from Western cultures, despite the emphasis placed on wellbeing in all corners of the globe. To meet the challenges and opportunities arising from cross-disciplinary research worldwide, the Well-Being for Planet Earth Foundation and the Gallup World Poll have joined forces to add more culturally relevant constructs and questions to existing Gallup modules. In this white paper, we review the discussion from the international well-being summit in Kyoto, Japan (August 2019), where nine such additions were proposed and highlight why a more global view of wellbeing is needed. Overall, the new items reflect a richer view of wellbeing than life satisfaction alone and include hedonic and eudaimonic facets of wellbeing, social wellbeing, the role of culture, community, nature, and governance. These additions allow for the measurement of a broader conceptualization of wellbeing, more refined and nuanced cross-cultural comparisons, and facilitate a better examination of the causes of variation in global wellbeing. The new Gallup World Poll additions will be trialled in 2020, with additional inclusions from this summit to be made in 2021.
\end{abstract}

Keywords: positive psychology, wellbeing, hedonia, eudaimonia, life satisfaction, culture

\section{Introduction}

The science of wellbeing has come a long way. Initially anchored in the field of psychology, it has since moved into fields like organizational development, health, education, economics, and policy expansion. Indeed, global policy makers are progressively adopting wellbeing as an overarching framework by which to assess, track, and respond to human development challenges and opportunities. Indices by which wellbeing is measured are thus critical, and need to be carefully reviewed and updated. For example, the World Happiness Report (WHR), which has garnered international attention for its national happiness rankings, and the Happy Planet Index, ranking environmentally sustainable wellbeing, assess wellbeing via the Gallup World Poll (GWP). Both reports rely on a single question: the Cantril Self-Anchoring Striving Scale (Cantril, 1965), also called Cantril's Ladder, which asks respondents to rate themselves on their current and future perceived quality or satisfaction with life, with the bottom of the 'ladder' representing low satisfaction/quality of life and the top, representing high satisfaction/quality of life. 
Although the Cantril's Ladder is a valid assessment of present perceived quality of life across global cultures, it is an incomplete measure of well-being. At the country-level, Cantril's Ladder is highly correlated with a nation's Gross Domestic Product (GDP) (Diener, Kahneman, Tov, \& Arora, 2010; Helliwell, Huang, \& Wang, 2017; Joshanloo, 2018; Joshanloo, Jovanovic, \& Taylor, 2019; Oishi \& Schimmack, 2010). This single score is also linked to several factors (e.g., personal freedom as well as healthcare, educational, and political functioning, Joshanloo et al., 2019). It is further considered a Western-centric metric of wellbeing reflecting Western populations used in most psychology research (Henrich, Heine, \& Norenzayan, 2010) and is limited in its ability to reflect ways in which wellbeing is experienced and understood worldwide (Lomas, 2015). Scholars have found that subjective wellbeing can be ordered along a single dimension from evaluative judgements of life (Cantril's ladder) on one end to experienced affect on the other (Diener, Kahneman, Arora, Harter, \& Tov, 2009; Diener, Ng, Harter, \& Arora, 2010). This ordering reveals that evaluative judgements are more highly related to income, standards of living, and luxury conveniences although meeting basic and psychosocial needs mediated the effects of income on life evaluation to a degree, while affect is more highly related to psychological needs, autonomy, social relationships, and fulfilment in daily tasks.

Wellbeing has also been thought of as a multidimensional set of constructs that are not reducible to a single facet (such as quality of life) (de Chavez, Backett-Milburn, Parry, \& Platt, 2005; Lomas, Hefferon, \& Ivtzan, 2015); it includes not only satisfaction with life, a cognitive appraisal of one's life, but positive emotions and psychological resources (such as meaning in life), together with considerations of social inequality, environmental degradation, and political freedom. For example, Morrison, Tay, and Diener (2011) found, using Gallup World Poll data that people tend to use proximate factors, such as one's job, health, or standard of living to judge their wellbeing when overall living conditions are satisfactory or when individualism is salient. In contrast, individuals are more likely to use perceived societal success to judge life satisfaction when life conditions are difficult or when collectivist norms form part of their culture. This suggests additional dimensions need emphasis in wellbeing appraisals, preferably through consensus and founded on empirical evidence proffered by the global academic community. This approach also means capturing the diverse influences that have hitherto been overlooked in existing measures and which matter to individuals and societies.

In the interests of advancing this aim, the authors recently participated in a three-day summit convened in August 2019 in Kyoto, Japan. Funded and facilitated by the Well-Being for Planet Earth Foundation (previously called the LiFull Foundation) and Gallup representatives, its principal goal was to add new items to the GWP to ensure its representativeness in global wellbeing perspectives. This means including additional concepts that have been omitted to date, such as the role of culture, community, governance, and nature. This white paper offers a summary of the proposed additions, including their rationale and future research potential. By offering these additions, we hope to complement the work of the World Happiness Report council and offer a truly comprehensive "World Wellbeing Report" in the years to come.

\subsection{What's wrong with the GDP as a measure of prosperity?}

While income (GDP) is an indicator of prosperity, it is not the only one, and the realization of its inadequacy in measuring social progress is growing (Adler \& Seligman, 2016; Lambert, Mulay-Shah, Warren, \& Younis, 2019; Nikolova, 2016; Stiglitz, Sen, \& Fitoussi, 2009; Uchida \& Oishi, 2016). Measuring the market value of goods and services tells us little about individual wellbeing and happiness, or who benefits when a nation's GDP increases. Costs to the environment or health are also not calculated; in fact, this is a constant criticism of positive 
psychology, the newly minted science of wellbeing, which focuses more on the psychological makeup of individuals and less on societal, political, and natural contexts in which they live (Kern et al., 2019; Mead et al., 2019). Further, while more income generates higher life satisfaction, this relationship does not hold true everywhere or in all conditions (Easterlin, 2015). For instance, a decrease in positive emotion due to rising ambitions and lost hopes for one's economy, coupled with failed leadership in delivering jobs and rising social equality, underscores what is known as the "unhappy development paradox" (Arampatzi, Burger, Ianchovichina, Röhricht, \& Veenhoven, 2015). Money is not all that matters; factors such as equality, access to opportunity, and feelings of respect can highlight what is happening in societies that a nation's GDP cannot.

\subsection{Why Does Wellbeing Matter?}

While this question has been answered by many researchers, a recap is helpful for those who remain unconvinced of its necessity as a matter of policy and global research. There are many reasons why wellbeing matters. First, individuals with greater wellbeing are known to generate greater social good and are easier on the public purse. For instance, they are more likely to save and control expenditures by consuming less (Guven, 2012). They are more likely to show compassion, empathy, and more prosocial behavior (Johnson \& Fredrickson, 2005; Nelson, 2009; Rand, Kraft-Todd, \& Gruber, 2015), be more socially engaged (Mehl, Vazire, Holleran, \& Clark, 2010; Richards \& Huppert, 2011) and volunteer to a greater degree (Priller \& Shupp, 2011; Son \& Wilson, 2012; Thoits \& Hewitt, 2001). More likely to make more ethical decisions (James \& Chymis, 2004), they also engage in less risky behavior, smoke less, and exercise more (Goudie, Mukherjee, De Neve, Oswald, \& Wu, 2012; Grant, Wardle, \& Steptoe, 2009; Huang \& Humphreys, 2012). Individuals with greater wellbeing also tend to be healthier and live longer (Boehm \& Kubzansky, 2012; Sin, 2016; Wiest, Schüz, Webster, \& Wurm, 2011). At school, greater wellbeing translates into better grades (Durlak, Weissberg, Dymnicki, Taylor, \& Schellinger, 2011; Suldo, Thalji, \& Ferron, 2011), while workplaces benefit with happier employees showing more productivity, engagement attitudes, and less sick time and absenteeism (Bockerman \& Ilmakunnas, 2012; Edmans, 2012; Harter, Schmidt, Asplund, Agrawal, \& Killham, 2010; Harter, Schmidt, \& Hayes, 2002; Judge, Thoreson, Bono, \& Patton, 2001; Krause, 2013; Oswald, Proto, \& Sgroi, 2012; Walsh, Boehm, \& Lyubomirsky, 2018).

\subsection{The Gallup World Poll (GWP)}

The Gallup World Poll (2005-present) contains a core survey component that carries over from year to year covering the range of overall wellbeing measurements on a continuum from evaluative judgements of life (Cantril's Ladder) to measures of affect and daily experiences (reflections on the previous day). The core instrument also includes measures of law and order, food and shelter, work quality, health, standard of living, citizen engagement, migration intentions, views of governance, and demographic variables. Additional items and modules are added based on current events and the needs of sponsoring entities. This current initiative seeks to expand the core content to fill gaps in wellbeing research that align with Eastern scholar's findings and views.

In World Poll countries, Gallup surveys residents using probability-based sampling methods. The samples are representative of the civilian, non-institutionalized national population, aged 15 and older in the vast majority of countries. Exceptions to national coverage include unsafe areas, very remote locations and low human-density areas. Typically, the sample size is 1,000 adults in most countries, while in the most populous nations such as China, India, and Russia, Gallup uses sample sizes of at least 2,000. The sampling of respondents and countries 
represents more than $95 \%$ of the global population on any given year. This broad coverage of the global population has led to improved interpretations of the relationships among many wellbeing variables, including life satisfaction, age, health, and income across societies for example (Deaton, 2008).

Gallup maintains a centralized level of research management and quality assurance coupled with country-specific knowledge provided by its Regional Research Directors. This centralisation offers a single point of contact and strong processes to ensure consistency, quality and transparency. The World Poll data collection is divided into seven regions. Each region (see box) is led by a Regional Research Director who is responsible for all phases of the research process in his or her portfolio of countries. The Regional Research Director also oversees data collection efforts, which are carried out by the local partners' field teams. Good logistics are key to collecting quality data in the most time-efficient manner. In face-to-face countries, Gallup's local data collection partners use a field plan to deploy their field teams most effectively across geographies. In telephone countries, local partners must also manage the phone sample carefully for maximum efficiency.

\subsection{Why Additions are Necessary}

Empirical research around wellbeing is rapidly growing. Indices must keep pace with these scientific developments by including broader constructs that contribute to wellbeing, such as the natural, social, and political settings in which humans live and thrive (Kern et al., 2019; Mead et al., 2019). Further, not only is the literature evolving, but non-Western research in particular is emerging, making salient a dearth of cross-cultural diversity in the science and measurement of wellbeing (Kim, Doiron, Warren, \& Donaldson, 2018). The predominant Western view of wellbeing has implications for which of its aspects are researched, upon whom the research is based, and what resulting norms emerge for what constitutes a good life. For example, crosscultural differences influence how societies define the self (Joshanloo, 2014), with individualism (a view of the self as independent and focused on the promotion of one's success and personal attributes) being predominant in the West, and collectivism (where self construals are interdependent, with value placed on maintaining relationships, fulfilling social roles, and sacrificing for a collective good) being predominant in the East.

With the exception of cross-cultural research, which tends to be relegated to the periphery of research findings, and the Gallup World Poll as well as a handful of other data collecting entities, much of the wellbeing research to date has largely been based on what have been called "WEIRD" samples, i.e., Western, Educated, Industrialized, Rich, and Democratic populations (Henrich et al., 2010) reflected in nearly 90\% of the published psychology research (Arnett, 2009; Christopher, Wendt, Marecek, \& Goodman, 2014; Rad, Martingano, \& Ginges, 2018). This Western-centricity of psychology needs to be challenged to make research and its findings more representative of all humans; moreover, representative research populations and a broader range of wellbeing constructs will align more accurately with how communities around the world view themselves (Kim et al., 2018) and reflect what truly comprises a good life.

\section{The Process}

A team of seven researchers was invited to the summit on August 5, 6, and 7, 2019. The summit took place at the Shunkoin Temple in Kyoto, Japan and was organized by the Well-Being for Planet Earth Foundation, a non-profit dedicated to making wellbeing science truly global and representative of all human views and perspectives. Invited participants were chosen for their range of cross-cultural research expertise, experience in developing measures and scales, in- 
depth knowledge of non-traditional and/or non-Western views of wellbeing, and leadership in philosophical and theoretical developments in the field of wellbeing. Participants presented their findings and proposed research initiatives, focused on addressing current gaps in the literature through the provision of context and content from non-Western regions of the world. They also collectively proposed alternative and/or additional topics for the existing GWP and formulated these as questionnaire items. These topics and items were discussed, debated, and voted upon. The list below includes the final selection. Questions 1 through 6 are those with the highest votes, which were put forward to Gallup for consideration. The remaining items (7 to 9 ) are those we felt were worthy of consideration for future editions of the poll.

\subsection{Proposed additions: Constructs, questions, and rationales}

Broadly, the constructs and items we recommend expand Gallup's current wellbeing measures of life satisfaction (i.e., Cantril's Ladder) and the ratio of high-arousal positive to negative emotions, measures which primarily assess hedonic wellbeing (Kahneman, Diener, \& Schwarz, 1999; Ryan \& Deci, 2001). With its focus on feeling good, experiencing pleasure, enjoyment, and comfort, and reducing pain, hedonic wellbeing is vital to human flourishing (Huta \& Ryan, 2010). Also crucial is eudaimonic wellbeing (Ryan \& Deci, 2001; Ryff \& Singer, 2008), using and developing the best in oneself (Huta \& Ryan, 2010), a definition of wellbeing with roots in Aristotle's virtue ethics that is concerned with mastery, purpose in life, and personal growth. While hedonic and eudaimonic wellbeing overlap and are distinct, each contributes to wellbeing in complementary ways (Huta \& Waterman, 2014; Ryan \& Huta, 2009) and are both necessary to living a full life (Joshanloo, 2016; Keyes, Shmotkin, \& Ryff, 2002; Ryan \& Deci, 2001). Our items reflect both orientations as well as the basic psychological needs posited by SelfDetermination Theory (SDT, Ryan \& Deci, 2000) that must be satisfied for individuals to flourish, namely: autonomy, competence, and relatedness.

While Gallup will unveil its final additions to the GWP in time for its 2020 wave and may modify the wording of items further, we have put forward a short list of additions we felt were:

(1) reflective of a comprehensive conceptualization of wellbeing, augmenting other wellbeing measures in the current literature;

(2) most pressing to capture as global data does not yet exist for these items;

(3) inclusive of a wider, richer, and more in-depth range of non-Western worldviews not currently captured by the poll;

(4) of emergent and dynamic interest as their relationships with other proposed concepts have not yet been examined;

(5) useful items from which policy makers and other decision makers could take action and,

(6) demonstrative of the true complexity of wellbeing, highlighting cultural, religious, or regional differences allowing for an examination of the factors that contribute to wellbeing across and within global societies.

\subsubsection{Proposal 1-Relationship to nature: "I feel connected to nature and all of life."}

The human need for relatedness goes beyond connecting with fellow humans; it extends to connecting with the greater-than-human natural world. Nature connectedness refers to an emotional sensibility that one is part of the larger cycle of life and broader natural environment (Leary, Tipsord, \& Tate, 2008; Mayer \& Frantz, 2004; Nisbet, Zelenski, \& Murphy, 2011). Across samples spanning four continents, empirical evidence has demonstrated that individuals who feel emotionally connected with nature enjoy enhanced levels of both hedonic and eudaimonic wellbeing (see meta-analyses by Capaldi, Dopko, \& Zelenski, 2014; Pritchard, Richardson, 
Sheffield, \& McEwan, 2019). Greater feelings of nature connectedness are associated with higher levels of happiness, life satisfaction, and positive emotions, in addition to higher levels of autonomy, personal growth, environmental mastery, meaning in life, and positive relations with others. Moreover, nature connectedness emerges as a significant, distinct predictor of many happiness indicators, over and above other types of human social relationships and connections (Zelenski \& Nisbet, 2014). With regard to eudaimonic wellbeing, nature connectedness emerges as either similar to or greater in predictive magnitude than socio-demographic and economic benchmarks (Martin et al., forthcoming).

In sum, nature connectedness matters to wellbeing and researchers have made a case for nature relatedness as a basic human psychological need in its own right (Baxter \& Pelletier, 2019; Hurly \& Walker, 2019). Further, meta-analytic results of studies utilizing samples from North and South America, Europe, Australasia, and Asia provide evidence for a robust, causal link between nature connectedness and pro-environmental behaviours and activities that protect the planet's wellbeing (Mackay \& Schmitt, 2019; Whitburn, Linklater, \& Abrahamse, 2019). Given this evidence, and in line with the summit's sponsor, the Well-Being for Planet Earth Foundation, we propose to include the item "I feel connected to nature and all of life".

\subsubsection{Proposal 2-Mastery: "I am capable of dealing with life's challenges."}

A sense of mastery is one aspect in the definition of eudaimonic wellbeing. Individuals who score high on this factor "have a sense of mastery and competence in managing the environment, control a complex array of external activities, make effective use of surrounding opportunities, and are able to choose/create contexts suitable to personal needs and values" (Ryff, 1995). Noted earlier, within Self-Determination Theory (Ryan \& Deci, 2000), a sense of competence or mastery is one of three basic human psychological needs. While some research supports these needs as evident across cultures (e.g., Chen et al., 2015), it has been suggested that the dimension of mastery may reflect more Western, individualistic notions, with non-Western cultures placing more emphasis on harmony with - rather than mastery of-their environment (Christopher, 1999; Joshanloo, 2013). Due to a lack of global data, however, it has been difficult to investigate this claim and its consequences. Measuring mastery on a global scale would enable a better quantification of the relative importance of mastery across different cultures, as well as its dynamic interplay with other aspects of well-being. We therefore propose the inclusion of the following item to assess self-perceived mastery: "I am capable of dealing with life's challenges".

\subsubsection{Proposal 3-Meaning in Life: "My daily activities seem worthwhile to me."}

The desire for meaning is widely characterized as a fundamental motivation (Frankl, 1963; Maslow, 1968; Williams, 2007) and cornerstone of eudaimonic wellbeing (Diener \& Seligman, 2004; Huta \& Ryan, 2010; Ryff \& Singer, 1998; Steger, 2012). High levels of meaning in life predict various wellbeing benefits including life satisfaction, positive emotions, high morale, vitality, resiliency after trauma, self-worth, personal growth, and environmental mastery, to name a few (see review, Steger, 2009). A consensus has emerged detailing meaning in life as a multidimensional construct comprising three distinct facets: purpose-feeling directed and motivated by goals, coherence - feeling as though one's life makes sense, and significancefeeling that one's life and activities matter (George \& Park, 2016; Heintzelman \& King, 2014; Martela \& Steger, 2016; Steger 2012). Although research has examined the purpose and coherence aspects of meaning, the significance aspect of meaning in life has been less studied. Still, research is emerging which suggests that a sense of significance, feeling that one's life matters and is worthwhile, is a central aspect of meaning (George \& Park, 2016). Having a life worth living is 
intimately connected with eudaimonia and aligned with the Japanese notion of ikigai, translated as a sense of "life worth living" (Sone et al., 2008, p. 709). It is important to note that "significance is not merely about any kind of positive and negative feelings in life, but about the sense of value that arises when we evaluate our lives" (Martela \& Steger, 2016. p. 538). In order to measure significance, this central aspect of meaning in life, we propose to include the item "My daily activities seem worthwhile to me".

\subsubsection{Proposal 4-Low-arousal emotions: "Did you feel calm and at peace yesterday?"}

As noted above, hedonic forms of wellbeing-often referred to as 'subjective wellbeing' (Diener, 1994) - are frequently operationalized as having two elements: a cognitive component, usually framed as 'life satisfaction' (Diener, Emmons, Larsen, \& Griffin, 1985) and an affective component, involving the ratio of positive to negative affect (Watson, Clark, \& Tellegen, 1988). Research into the affective component tends to emphasize and prioritize high arousal forms of positive affect. However, such trends reflect the influence of researchers and participants from Western nations, since other cultures, particularly Eastern ones, may place greater value on low arousal positive emotions (Leu, Wang, \& Koo, 2011), such as calmness and contentment. Possible explanations include a certain 'fear' or wariness of high arousal emotions in such cultures (Joshanloo, 2013). That said, low arousal positive emotions may be more universally valued than widely realized. For instance, analyzing lay perceptions of happiness across five continents, Delle Fave et al. (2016) found that the most prominent psychological definition was a sense of 'inner harmony', featuring three subcomponents: inner peace; contentment; and balance. We align with such findings, although we prefer to separate these subcomponents into two items: peace and contentment (this item), and balance (the next). In order to measure low arousal emotions, we propose to include the item, "Did you feel calm and at peace yesterday?".

\subsubsection{Proposal 5-Balance and harmony: "The various aspects of my life are in balance."}

A key insight from the summit was the recognition of the importance of balance and harmony (see Lomas (forthcoming) for a conceptual review). These concepts are central to Eastern conceptualizations of wellbeing (Wong, 2011), reflecting the influence of traditions such as Taoism (Fang, 2012). At the same time, Delle Fave et al.'s (2016) research suggests their importance might be more universally recognized. While Della Fave et al. grouped balance together with peace and contentment into an overall construct of inner harmony, we separate low arousal positive emotions (the previous item) from our conceptualization of balance and harmony. Our discussions of the latter centered on these qualities not as forms of low arousal affect, but rather as forms of dynamic equilibrium between dialectically related-contrasts across many aspects of life. These include (but are not limited to) subjective emotional states, character, activities, and self-other relations.

First, a full life involves a range of emotions, including negatively-valenced ones, as illustrated by the paradigm of 'second wave' positive psychology (Lomas \& Ivtzan, 2016). Thus, there is a time for joy and a time for sadness, for acceptance and for anger, and so on, and flourishing involves an optimal subjective balance of these oppositional qualities. Second, in terms of character, following Aristotle's notion of the 'golden mean', virtue and excellence are found in the optimal balance between extremes (courage, for instance, treading a middle line between timidity and rashness) (Kristjánsson, 2006). Third, with activities, wellbeing involves an appropriate balance between various life elements, as per the concept of 'work-life balance' (Guest, 2002). Finally, good self-other relations include striking a balance between prioritizing one's individual needs with those of others (and also of the natural world). A flourishing life 
involves many such balancing acts, with the overall configuration of these ideally being in a pattern of harmony. In order to measure this perceived balance and harmony in life, we propose the item "The various aspects of my life are in balance" (adapted from Kjell, Daukantaite, Hefferon, and Sikström's (2016) Harmony in Life Scale).

\subsubsection{Proposal 6-Relationship to group: "My happiness depends on the happiness of people close to me."}

Although individualism is often seen as a characteristic of Western cultures, rates of individualism are growing worldwide as a function of increasing globalization (Hamamura, 2012; Santos, Varnum, \& Grossmann, 2017). Interestingly, parallel rates of collectivism are not in decline (e.g., Mesoudi, Magid, \& Hussain, 2016) and much of the world remains collectively organized. Given that much of the psychology research stems from individualistic nations (Henrich et al., 2010), the orientation to 'other' is often treated as more of an anomaly than a norm. Collectivism reflects the view that the self is interdependent, related, and less differentiated from others than is the case in more individualistic contexts. In collectivistic settings, there tends to be a priority on relationships, social duties and roles, and ensuring that group prosperity and harmony take precedence (Grossman \& $\mathrm{Na}, 2014$ ). These narratives are expressed in norms, behaviors, socialization practices, and even how information is processed (Mesoudi et al., 2016). To capture what is still the collectivistic norm in many cultures, the proposed item reflects the interdependency individuals have with one another, and that individual wellbeing is tightly bound to collective wellbeing. To measure this relationship to the group, we propose to include the item "My happiness depends on the happiness of people close to $\mathrm{me}^{\prime \prime}$.

2.1.7 Proposal 7-Relationship with government: "To what extent do you feel that your government and/or society respects people for who they are (for example, their culture, religion, sexual, or political orientation)?"

As noted, SDT proposes that autonomy is a basic human need (Ryan \& Deci, 2000). In line with this, wellbeing tends to increase with greater political, economic, and personal freedoms (Inglehart, Foa, Peterson, \& Welzel, 2008; Ngamaba \& Soni, 2018; Verme, 2009; Welzel \& Inglehart, 2010). As such, it matters greatly the extent to which governments and societies are open, inclusive, and demonstrative of respect towards individuals with alternative lifestyles, cultures, religions, political orientations, and socioeconomic status. For instance, studies show that minorities (e.g., sexual minorities) are more satisfied in welcoming societies that are tolerant and inclusive (versus discriminatory, indifferent, or hostile). Further, it seems that this relationship between life satisfaction and tolerant, inclusive societies is true for everyone, not only for individuals of minority groups (Berggren, Bjørnskov, \& Nilsson, 2017; Kogan, Shen, \& Siegert, 2018). Studies support that social exclusion decreases subjective wellbeing (Verkuyten, 2008) and discrimination based on sexual minority status, for example, is costly to individuals in terms of life satisfaction and subjective wellbeing as they suffer from disparities in employment, friendships, physical health, income, and social supports (Conlin, Douglass, \& Ouch, 2019; Powdthavee \& Wooden, 2015). These same relationships between subjective wellbeing and discrimination against racial minorities is also evident (Cormack, Stanley, \& Harris, 2018; Paradies et al., 2015; Yoo, Kim, \& Lee, 2018). In order to measure the relationship between individuals and their government and society (i.e., as either upholding or infringing upon their personal freedoms and dignities), we propose to include the item "To what extent do you feel that your government and/or society respects people for who they are (for example, their culture, religion, sexual, or political orientation)?" 


\subsubsection{Proposal 8-Leisure: "To what extent are you satisfied with how you spend your free time?"}

Aristotle believed that leisure, "time away from unpleasant obligations" (Stebbins, 2001, pg. 4), was central to a satisfying life, in part because its activities were freely chosen. Modern theories not only refer to the freedom of choice inherent in leisure activity (Gunter \& Gunter, 1980; Iso-Ahola, 1988; Kelly, 1972), linking it to the satisfaction of our basic human need for autonomy, but theories and research also refer to the satisfaction of needs related to meaning in life, mastery, and relatedness that leisure offers (Newman, Tay, \& Deiner, 2014). While frequency of engaging in leisure activities is associated with happiness and life satisfaction (e.g., Newman et al., 2014; Sheldon \& Lyubomirsky, 2004), it is leisure satisfaction, how pleased one is with those experiences, that is paramount to wellbeing (see review, Kuykendall, Boemerman, \& Zhu, 2018).

For instance, meta-analytic results of longitudinal and experimental studies suggest a causal effect of leisure satisfaction on hedonic wellbeing (Kuykendall, Tay, \& $\mathrm{Ng}$, 2015). While such studies involved samples from many countries (i.e., Australia, Canada, England, Finland, Germany, Japan, Korea, Netherlands, Taiwan, and the United States), global data is needed. Moreover, linkages between leisure satisfaction and markers of eudaimonic well-being have yet to be examined. It is possible that cultural views regarding the value of work and leisure could attenuate or enhance the relationship between leisure satisfaction and wellbeing. Yet, no significant difference in the strength of this relationship was evident in Kuykendall and colleagues' (2015) meta-analysis across samples from countries that highly value leisure (e.g., European countries) compared to nations which value it to a lesser extent (e.g., United States). Additional data is needed to examine if these results hold around the globe. In order to measure leisure satisfaction, we propose to include the item "To what extent are you satisfied with how you spend your free time?".

\subsubsection{Proposal 9-Resilience: "When life is difficult, I recover quickly."}

Resilient individuals are those who bounce back from difficulties, adapt to changing demands of stressful experiences, and move forward with few apparent disruptions to their daily functioning (Carver, 1998; Fletcher \& Sarkar, 2013). Many studies demonstrate that resiliency is associated with greater happiness and satisfaction with life in the short-term and over one's lifetime (e.g., Doyle et al., 2015; Haddadi \& Besharat, 2010; Seery, Holman, \& Silver, 2010; Smith \& Holllinger-Smith, 2015). Resilient individuals still experience a range of negative emotions during stressful times, just as their less resilient counterparts do; indeed, highly resilient older adults show greater emotional complexity (i.e., the co-occurrence of positive and negative emotions) compared to the less resilient (Ong, Bergeman, \& Boker, 2009).

Yet, as noted earlier in relation to balance and harmony, a full life necessarily includes a range of emotion (Lomas \& Ivtzan, 2016). The strength that resilient individuals exhibit during stressful times comes not from ignoring negative emotions evoked by trauma and stress, rather their strength seems to lie in their ability to draw on positive emotions to regulate their overall affect (Tugade \& Fredrickson, 2004). In turn, resiliency itself produces positive emotions, leading to an upward cycle of wellbeing (Cohn, Fredrickson, Brown, Mikels, \& Conway, 2009; Zautra, Johnson, \& Davis, 2005). Others have suggested that meaning in life may be a critical link to resilience (Weathers, Aiena, Blackwell, \& Schulenberg, 2016). While Southwick and Charney (2018) identified meaning in life as one of many factors correlated with resiliency, there is a paucity of studies examining the links between them. When added to Gallup's existing measures of positive affect and life satisfaction, inclusion of our suggested item on meaning in life and resilience could help elucidate relationships among these factors across nations. To measure resiliency, we propose to include the item "When life is difficult, I recover quickly." 


\title{
2.2 Research Potential of Our Proposed Additions
}

The research potential stemming from an expanded global measure of wellbeing is immense. While the concept of wellbeing is much richer than life satisfaction alone, the lack of global data on hedonic and eudaimonic facets of wellbeing has hampered progress in the field. The inclusion of these newly proposed items not only allows for the measurement of a broader wellbeing definition across the world, but also allows for refined and nuanced cross-cultural comparisons of wellbeing. For example, having multiple items that measure different aspects of wellbeing creates novel opportunities for examining the factor-structure or network-structure of wellbeing across different countries and cultures. Additionally, given the abundance of other related measures present in the GWP, the inclusion of these new wellbeing items will allow for a better examination of the causes of variation in wellbeing across the globe. It is our hope that these new additions will serve to push the wellbeing agenda to the forefront of government policy, and, once data has been gathered, offer evidence to address current gaps in our knowledge.

\section{Conclusion}

The utility of the GWP's assessment of wellbeing across the globe, and national reports which stem from it such the WHR and Happy Planet Index, cannot be overlooked. The GWP has helped to garner greater interest in wellbeing as a topic of serious academic concern, as well as capture the attention of governments in its use as an overarching policy framework. As one of the first global wellbeing assessments, it has raised the profile of wellbeing everywhere. However, it is now time for a new, comprehensive measure of global wellbeing to be used to successfully reflect the preoccupations and opportunities of societies and individuals across the world and truly advance a representative human science of wellbeing. We hope to have captured these missing nuances in our proposed items and stimulate the growing and ever evolving body of research to capture such new developments in both conceptualizations and measurements.

\author{
Authors \\ Louise Lambert \\ United Arab Emirates University \\ 1tlamber@yahoo.com \\ Tim Lomas \\ University of East London \\ Margot P van de Weijer \\ VU University \\ Holli Anne Passmore \\ University of Derby \\ Mohsen Joshanloo \\ The University of Melbourne \\ Jim Harter \\ Gallup \\ Yoshiki Ishikawa \\ Well-Being for Planet Earth Foundation
}




\section{Alden Lai}

New York University

Takuya Kitagawa

Rakuten

Dominique Chen

Waseda University

Takafumi Kawakami

Shunkoin Temple

Hiroaki Miyata

Keio University

Ed Diener

University of Virginia

University of Utah

\section{Publishing Timeline}

Received 27 October 2019

Accepted 20 January 2020

Published 1 June 2020

\section{References}

Adler, A., \& Seligman, M. E. P. (2016). Using wellbeing for public policy: Theory, measurement, and recommendations. International Journal of Wellbeing, 6(1), 1-35. https://doi.org/10.5502/ijw.v6i1.429

Arampatzi, E., Burger, M. J., Ianchovichina, E., Röhricht, T., \& Veenhoven, R. (2015). Unhappy development: Dissatisfaction with life on the eve of the Arab spring. World Bank Policy Research Working Paper No. 7488. Retrieved from https://ssrn.com/abstract $=2690017$

Arnett, J. J. (2009). The neglected 95\%, a challenge to psychology's philosophy of science. American Psychologist, 64(6), 571-574. https://doi.org/10.1037/a0016723

Baxter, D. E., \& Pelletier, L. G. (2019). Is nature relatedness a basic human psychological need? A critical examination of the extant literature. Canadian Psychology, 60, 21-34. doi:10.1037/cap0000145

Berggren, N., Bjørnskov, C., \& Nilsson, T. (2016). What aspects of society matter for the quality of life of a minority? Global evidence from the new Gay Happiness Index. Social Indicators Research, 132(3), 1163-1192. doi:10.1007/s11205-016-1340-3

Bockerman, P., \& Ilmakunnas, P. (2012). The job-satisfaction-productivity nexus: A study using matched survey and register data. Industrial \& Labor Relations Review, 65, 244-262. https://doi.org/10.1177/001979391206500203

Boehm, J. K., \& Kubzansky, L. D. (2012). The heart's content: The association between positive psychological wellbeing and cardiovascular health. Psychological Bulletin, 138(4), 655-691. https://doi.org/10.1037/a0027448

Cantril, H. (1965). The pattern of human concerns. New Brunswick, NJ: Rutgers University Press.

Capaldi, C. A., Dopko, R. L., \& Zelenski, J. M. (2014). The relationship between nature connectedness and happiness: A meta-analysis. Frontiers in Psychology, 5, 976. doi:10.3389/fpsyg.2014.00976

Carver, C. S. (1998). Resilience and thriving: Issues, models and linkages. Journal of Social Issues, 54, $245-$ 266. https://doi.org/10.1111/j.1540-4560.1998.tb01217.x

Chen, B., Vansteenkiste, M., Beyers, W., Boone, L., Deci, E. L., der Kaap-Deeder, J., ... Verstuyf, J. (2015). Basic psychological need satisfaction, need frustration, and need strengths across four cultures. Motivation and Emotion, 39, 216-236. doi:10.1007/s11031-014-9450-1 
Christopher, J. C. (1999). Situating psychological well-being: Exploring the cultural roots of its theory and research. Journal of Counseling \& Development, 77(2), 141-152. https://doi.org/10.1002/j.15566676.1999.tb02434.x

Christopher, J. C., Wendt, D. C., Marecek, J., \& Goodman, D. M. (2014). Critical cultural awareness: Contributions to a globalizing psychology. American Psychologist, 69(7), 645-655. https://doi.org/10.1037/a0036851

Cohn, M. A., Fredrickson, B. L., Brown, S. L., Mikels, J. A., \& Conway, A. M. (2009). Happiness unpacked: Positive emotions increase life satisfaction by building resilience. Emotions, 9, 361-368. https://doi.org/10.1037/a0015952

Conlin, S. E., Douglass, R. P., \& Ouch, S. (2019). Discrimination, subjective wellbeing, and the role of gender: A mediation model of LGB minority stress. Journal of Homosexuality, 66(2), 238-259. doi: 10.1080/00918369.2017.1398023

Cormack, D., Stanley, J., \& Harris, R. (2018). Multiple forms of discrimination and relationships with health and wellbeing: Findings from national cross-sectional surveys in Aotearoa/New Zealand. International Journal for Equity in Health, 17, Article 26. https://doi.org/10.1186/s12939-018-0735-y

de Chavez, A. C., Backett-Milburn, K., Parry, O., \& Platt, S. (2005). Understanding and researching wellbeing: Its usage in different disciplines and potential for health research and health promotion. Health Education Journal, 64(1), 70-87. https://doi.org/10.1177/001789690506400108

Deaton, A. (2008). Income, health, and well-being around the world: Evidence from the Gallup World Poll. Journal of Economic Perspectives, 22(2), 53-72. https://doi.org/10.1257/jep.22.2.53

Delle Fave, A., Brdar, I., Wissing, M. P., Araujo, U., Castro Solano, A., Freire, T., ... Nakamura, J. (2016). Lay definitions of happiness across nations: The primacy of inner harmony and relational connectedness. Frontiers in Psychology, 7, 30. https://doi.org/10.3389/fpsyg.2016.00030

Diener, E. (1994). Assessing subjective well-being: Progress and opportunities. Social Indicators Research, 31(2), 103-157. https://doi.org/10.1007/BF01207052

Diener, E., Emmons, R. A., Larsen, R. J., \& Griffin, S. (1985). The satisfaction with life scale. Journal of Personality Assessment, 49(1), 71-75. https://doi.org/10.1207/s15327752jpa4901_13

Diener, E., Kahneman, D., Arora, R., Harter, J., \& Tov, W. (2009). Income's differential influence on judgments of life versus affective well-being. In E. Diener (Ed.), Assessing well-being (pp. 233-246), Social Indicators Research Series (vol. 39). Dordrecht: Springer.

Diener, E., Kahneman, D., Tov, W., \& Arora, R. (2010). Income's association with judgments of life versus feelings. In E. Diener, J. Helliwell, \& D. Kahneman (Eds.), International differences in well-being (pp. 3-15). New York: Oxford University Press. https://doi.org/10.1093/acprof:oso/9780199732739.003.0001

Diener, E., Ng, W., Harter, J., \& Arora, R. (2010). Wealth and happiness across the world: Material prosperity predicts life evaluation, whereas psychosocial prosperity predicts positive feeling. Journal of Personality and Social Psychology, 99(1), 52-61. doi: 10.1037/a0018066.

Diener, E., \& Seligman, M. E. P. (2004). Beyond money: Toward an economy of well-being. Psychological Science in the Public Interest, 5, 1-31. https://doi.org/10.1111/j.0963-7214.2004.00501001.x

Doyle, N., MacLachlan, M., Fraser, A., Stilz, R., Lismont, K., ... McVeigh, J. (2015). Resilience and wellbeing amongst seafarers: Cross-sectional study of crew across 51 ships. International Archives of Occupational and Environmental Health, 89, 199-209. https://doi.org/10.1007/s00420-015-1063-9

Durlak, J. A., Weissberg, R. P., Dymnicki, A. B., Taylor, R. D., \& Schellinger, K. B. (2011). The impact of enhancing students' social and emotional learning: A meta-analysis of school-based universal interventions. Child Development, 82(1), 405-432. doi:10.1111/j.1467-8624.2010.01564.x

Easterlin, R. A. (2015). Happiness and economic growth: The evidence. In W. Glatzer, L. Camfield, V. Møller, \& M. Rojas (Eds.), Global handbook of quality of life: Exploration of wellbeing of nations and continents (pp. 283-299). New York, NY: Springer.

Edmans, A. (2012). The link between job satisfaction and firm value, with implications for corporate social responsibility. Academy of Management Perspectives, 26(4), 1-19. https://doi.org/10.5465/amp.2012.0046

Fang, T. (2012). Yin Yang: A new perspective on culture. Management and Organization Review, 8(1), $25-$ 50. https://doi.org/10.1111/j.1740-8784.2011.00221.x 
Fletcher, D., \& Sarkar, M. (2013). Psychological resilience: A review and critique of definitions, concepts, and theory. European Psychologist, 18, 12-23. doi:10.1027/1016-9040/a000124

Frankl, V. E. (1963). Man's search for meaning. New York, NY: First Washington Square Press.

George, L. S., \& Park, C. L. (2016). Meaning in life as comprehension, purpose, and mattering: Toward integration and new research questions. Review of General Psychology, 20, 205-220. doi:10.1037/pr0000077

Goudie, R., Mukherjee, S., De Neve, J.-E., Oswald, A. J., \& Wu, S. (2012). Happiness as a driver of riskavoiding behavior. The Centre for Economic Performance, Discussion Paper No. 1126. Retrieved from http://cep.lse.ac.uk/pubs/download/dp1126.pdf

Grant, N., Wardle, J., \& Steptoe, A. (2009). The relationship between life satisfaction and health behavior: A cross-cultural analysis of young adults. International Journal of Behavioral Medicine, 16, 259-268. https://doi.org/10.1007/s12529-009-9032-x

Grossmann, I., \& Na, J. (2014). Research in culture and psychology: Past lessons and future challenges. Wiley Interdisciplinary Reviews: Cognitive Science, 5, 1-14. https://doi.org/10.1002/wcs.1267

Guest, D. E. (2002). Perspectives on the study of work-life balance. Social Science Information, 41(2), 255279. https://doi.org/10.1177/0539018402041002005

Gunter, B. G., \& Gunter, N. C. (1980). Leisure styles: A conceptual framework for modern leisure. The Sociological Quarterly, 21, 361-374. doi:10.1111/j.1533-8525.1980.tb00618.x

Guven, C. (2012). Reversing the question: Does happiness affect consumption and savings behavior? Journal of Economic Psychology, 33(4), 701-717. https://doi.org/10.1016/j.joep.2012.01.002

Haddadi, P., \& Besharat, M. A. (2010). Resilience, vulnerability and mental health. Procedia: Social and Behavioural Sciences, 5, 639-642. https://doi.org/10.1016/j.sbspro.2010.07.157

Hamamura, T. (2012). Are cultures becoming individualistic? A cross-temporal comparison of individualism-collectivism in the United States and Japan. Personality and Social Psychology Review, 16, 3-24. doi:10.1177/10888 68311411587

Harter, J. K., Schmidt, F. L., \& Hayes, T. L. (2002). Business-unit-level relationship between employee satisfaction, employee engagement, and business outcomes: A meta-analysis. Journal of Applied Psychology, 87(2), 268-279. https://doi.org/10.1037/0021-9010.87.2.268

Harter, J. K., Schmidt, F. L., Asplund, J. W., Killham, E. A., \& Agrawal, S. (2010). Causal impact of employee work perceptions on the bottom line of organizations. Perspectives on Psychological Science, 5(4), 378389. https://doi.org/10.1177/1745691610374589

Heintzelman, S. J., \& King, L. A. (2014). Life is pretty meaningful. American Psychologist, 69, 561-574. https://doi.org/10.1037/a0035049

Helliwell, J., Huang, H., \& Wang, S. (2017). Social foundations of world happiness. In J. Helliwell, R. Layard, \& J. Sachs (Eds.), World Happiness Report 2017. Retrieved from: https://s3.amazonaws.com/happiness-report/2017/HR17.pdf

Henrich, J., Heine, S. J., \& Norenzayan, A. (2010). The weirdest people in the world? Behavioral and Brain Sciences, 33(2-3), 61-83. https://doi.org/10.1017/S0140525X0999152X

Huang, H., \& Humphreys, B. R. (2012). Sports participation and happiness: Evidence from US microdata. Journal of Economic Psychology, 33(4), 776-793. https://doi.org/10.1016/j.joep.2012.02.007

Hurly, J., \& Walker, G. J. (2019). Nature in our lives: Examining the human need for nature relatedness as a basic psychological need. Journal of Leisure Research, 50, 290-310. doi:10.1080/00222216.2019.1578939

Huta, V., \& Ryan, R. M. (2010). Pursuing pleasure or virtue: The differential and overlapping well-being benefits of hedonic and eudaimonic motives. Journal of Happiness Studies, 11, 735-762. doi:10.1007/s10902-009-171-4

Huta, V., \& Waterman, A. S. (2014). Eudaimonia and its distinction from hedonia: Developing a classification and terminology for understanding conceptual and operational definitions. Journal of Happiness Studies, 15, 1425-1456. doi:10.100/s10902-013-9485-0

Inglehart, R., Foa, R., Peterson, C., \& Welzel, C. (2008). Development, freedom and rising happiness: A global perspective 1981-2006. Perspectives on Psychological Science, 3(4), 264-285. doi: 10.1111/j.17456924.2008.00078.x 
Iso-Ahola, S. (1988). The social psychology of leisure: Past, present, and future research. In L. A. Barnett (Ed.), Research about leisure (pp. 76-93). Champaign, IL: Sagamo.

James H. S. Jr., \& Chymis A. G. (2004). Are happy people ethical people? Evidence from North America and Europe (Working Paper No. AEWP 2004-08). Department of Agricultural Economics. Retrieved from http://ageconsearch.umn.edu/bitstream/26034/1/wp040008.pdf

Johnson, K. J., \& Fredrickson, B. L. (2005). "We all look the same to me": Positive emotions eliminate the own-race bias in face recognition. Psychological Science, 16, 875-881. https://doi.org/10.1111/j.14679280.2005.01631.x

Joshanloo, M. (2013). The influence of fear of happiness beliefs on responses to the satisfaction with life scale. Personality and Individual Differences, 54(5), 647-651. https://doi.org/10.1016/j.paid.2012.11.011

Joshanloo, M. (2014). Eastern conceptualizations of happiness: Fundamental differences with Western views. Journal of Happiness Studies, 15(2), 475-493. https://doi.org/10.1007/s10902-013-9431-1

Joshanloo, M. (2016). Revisiting the empirical distinction between hedonic and eudaimonic aspects of wellbeing using exploratory structural equation modeling. Journal of Happiness Studies, 17(5), 2023-2036. https://doi.org/10.1007/s10902-015-9683-z

Joshanloo, M. (2018). Optimal human functioning around the world: A new index of eudaimonic wellbeing in 166 nations. British Journal of Psychology, 109(4), 637-655.

Joshanloo, M., Jovanović, V., \& Taylor, T. (2019). A multidimensional understanding of prosperity and well-being at country level: Data-driven explorations. PLoS ONE 14(10): e0223221. https://doi.org/10.1371/journal.pone.0223221

Judge, T. A., Thoresen, C. J., Bono, J. E., \& Patton, G. K. (2001). The job satisfaction-job performance relationship: A qualitative and quantitative review. Psychological Bulletin, 127(3), 376-407. https://doi.org/10.1037/0033-2909.127.3.376

Kelly, J. R. (1972). Work and leisure: A simplified paradigm. Journal of Leisure Research, 4, 50-62. https://doi.org/10.1080/00222216.1972.11970057

Kern, M. L., Williams, P., Spong, C., Colla, R., Sharma, K., Downie, A., ... Oades, L. G. (2019). Systems informed positive psychology. The Journal of Positive Psychology, 1-11. doi:10.1080/17439760.2019.1639799

Kristjánsson, K. (2006). "Emotional intelligence" in the classroom? An Aristotelian critique. Educational Theory, 56(1), 39-56. https://doi.org/10.1111/j.1741-5446.2006.00002.x

Kahneman, D., Diener, E., \& Schwarz, N. (Eds.). (1999). Well-being: Foundations of hedonic psychology. New York, NY: Russell Sage Foundation.

Keyes, C. L., Shmotkin, D., \& Ryff, C. D. (2002). Optimizing well-being: The empirical encounter of two traditions. Journal of Personality and Social Psychology, 82(6), 1007-1022. https://doi.org/10.1037/00223514.82.6.1007

Kim, H., Doiron, K. M., Warren, M. A., \& Donaldson, S. I. (2018). The international landscape of positive psychology research: A systematic review. International Journal of Wellbeing, 8(1), 50-70. doi:10.5502/ijw.v8i1.651

Kjell, O., Daukantaitè, D., Hefferon, K., \& Sikström, S. (2016). The harmony in life scale complements the satisfaction with life scale: Expanding the conceptualization of the cognitive component of subjective well-being. Social Indicators Research, 126(2), 893-919. https://doi.org/10.1007/s11205-015-0903-z

Kogan, I., Shen, J., \& Siegert, M. (2018). What makes a satisfied immigrant? Host-country characteristics and immigrants' life satisfaction in eighteen European countries. Journal of Happiness Studies, 19(6), 1783 - 1809. doi:10.1007/s10902-017-9896-4

Krause, A. (2013). Don't worry, be happy? Happiness and reemployment. Journal of Economic Behavior \& Organization, 96(C), 1-20. https://doi.org/10.1016/j.jebo.2013.09.002

Kuykendall, L., Boemerman, L., \& Zhu, Z. (2018). The importance of leisure for subjective well-being. In E. Diener, S. Oishi, \& L. Tay (Eds.), Handbook of well-being. Salt Lake City, UT: DEF Publishers.

Kuykendall L., Tay, L., \& Ng, V. (2015). Leisure engagement and subjective well-being: A meta-analysis. Psychological Bulletin, 141, 364-403. doi:10.1037/a0038508

Lambert, L., Mulay-Shah, A., Warren, M. A., \& Younis, Y. (2019). The pursuit of national wellbeing policies across the GCC: The what, how, and why? In L. Lambert, \& N. Pasha-Zaidi (Eds.), Positive psychology 
in the Middle East/North Africa: Research, policy, and practise (pp. 11-35). Cham, Switzerland: Springer.

Leary, M. R., Tipsord, J. M., \& Tate, E. B. (2008). Allo-inclusive identity: Incorporating the social and natural worlds into one's sense of self. In H. A. Wayment \& J. J. Bauer (Eds.), Transcending self-interest: Psychological explorations of the quiet ego (pp. 137-147). Washington, DC: APA. https://doi.org/10.1037/11771-013

Leu, J., Wang, J., \& Koo, K. (2011). Are positive emotions just as "positive" across cultures? Emotion, 11(4), 994-999. https://doi.org/10.1037/a0021332

Lomas, T. (forthcoming). Life balance and harmony.

Lomas, T. (2015). Positive cross-cultural psychology: Exploring similarity and difference in constructions and experiences of wellbeing. International Journal of Wellbeing, 5(4), 60-77. doi:10.5502/ijw.v5i4.437

Lomas, T., Hefferon, K., \& Ivtzan, I. (2015). The LIFE model: A meta-theoretical conceptual map for applied positive psychology. Journal of Happiness Studies, 16(5), 1347-1364. https://doi.org/10.1007/s10902014-9563-y

Lomas, T., \& Ivtzan, I. (2016). Second wave positive psychology: Exploring the positive-negative dialectics of wellbeing. Journal of Happiness Studies, 17(4), 1753-1768. https://doi.org/10.1007/s10902-015-9668$\mathrm{y}$

Mackay, C. M. L., \& Schmitt, M. T. (2019). Do people who feel connected to nature do more to protect it? A meta-analysis. Journal of Environmental Psychology, 65. doi:10.1016/j.jenvp.2019.101323

Martela, F., \& Ryan, R. M. (2014). The benefits of benevolence: Basic psychological needs, beneficence, and the enhancement of wellbeing. Journal of Personality, 84, 750-764. doi:10.1111/jopy.12215

Martela, F., \& Steger, M. F. (2016). The three meanings of meaning in life: Distinguishing coherence, purpose, and significance. The Journal of Positive Psychology, 11, 531-545. doi:10.1080/17439760.2015.1137623

Martin, L., White, M. P., Hunt, A., Richardson, M., Pahl, S., \& Burt, J. (forthcoming). Nature contact, nature connectedness and associations with health, wellbeing and pro-environmental behaviors.

Maslow, A. H. (1968). Toward a psychology of being (2nd ed.). New York, NY: John Wiley.

Mayer, F. S., \& Frantz, C. M. (2004). The Connectedness to Nature Scale: A measure of individuals' feeling in community with nature. Journal of Environmental Psychology, 24, 504-515. doi:10.1016/j.jenvp.2004.10.001

Mead, J., Fisher, Z., Wilkie, L., Gibbs, K., Pridmore, J., Tree, J., \& Kemp, A. (2019). Rethinking wellbeing: Toward a more ethical science of wellbeing that considers current and future generations. Authorea, https://doi.org/10.22541/au.156649190.08734276 Retrieved from https://www.authorea.com/users/9886/articles/388348-rethinking-wellbeing-toward-a-more-ethicalscience-of-wellbeing-that-considers-current-and-future-generations

Mehl, M. R., Vazire, S., Holleran, S. E., \& Clark, C. S. (2010). Eavesdropping on happiness: Wellbeing is related to having less small talk and more substantive conversations. Psychological Science, 21(4), 539 541. https://doi.org/10.1177/0956797610362675

Mesoudi, A., Magid, K., \& Hussain, D. (2016). How do people become W.E.I.R.D.? Migration reveals the cultural transmission mechanisms underlying variation in psychological processes. PLoS ONE 11(1), e0147162. https://doi.org/10.1371/journal.pone.0147162

Morrison, M., Tay, L., \& Diener, E. (2011). Subjective well-being and national satisfaction: Findings from a worldwide survey. Psychological Science, 22(2), 166-171. https://doi.org/10.1177/0956797610396224

Nelson, D. (2009). Feeling good and open-minded: The impact of positive affect on cross cultural empathic responding. Journal of Positive Psychology, 4, 53-63. https://doi.org/10.1080/17439760802357859

Newman, D. B., Tay, L., \& Diener, E. (2014). Leisure and subjective well-being: A model of psychological mechanisms as mediating factors. Journal of Happiness Studies, 15, 555-578. https://doi.org/10.1007/s10902-013-9435-x

Ngamaba, K. H., \& Soni, D. (2018). Are happiness and life satisfaction different across religious groups? Exploring determinants of happiness and life satisfaction. Journal of Religion and Health, 57(6), 21182139. https://doi.org/10.1007/s10943-017-0481-2

Nikolova, M. (2016). Happiness and development. IZA Discussion Paper No. 10088. Retrieved from 
https://ssrn.com/abstract=2819369

Nisbet, E. K., Zelenski, J. M., \& Murphy, S. A. (2011). Happiness is in our nature: Exploring nature relatedness as a contributor to subjective well-being. Journal of Happiness Studies, 12, 303-322. doi:10.1007/s10902-010-9197-7

Oishi, S., \& Schimmack, U. (2010). Culture and well-being: A new inquiry into the psychological wealth of nations. Perspectives on Psychological Science, 5, 463-471. https://doi.org/10.1177/1745691610375561

Ong, A. D., Bergeman, C. S., \& Boker, S. M. (2009). Resilience comes of age: Defining features in later adulthood. Journal of Personality, 77, 1777-1804. https://doi.org/10.1111/j.1467-6494.2009.00600.x

Ott, J. C. (2010). Good governance and happiness in nations: Technical quality precedes democracy and quality beats size. Journal of Happiness Studies, 11(3), 353-368. https://doi.org/10.1007/s10902-0099144-7

Oswald, A. J., Proto, E., \& Sgroi, D. (2012). Happiness and productivity. University of Warwick. Retrieved from http://www.andrewoswald.com/docs/6MayOsProtoSgroi2012.pdf

Paradies, Y., Ben, J., Denson, N., Elias, A., Priest, N., Pieterse, A., \& Gee, G. (2015). Racism as a determinant of health: A systematic review and meta-analysis. PloS One, 10(9), e0138511. https://doi.org/10.1371/journal.pone.0138511

Powdthavee, N., \& Wooden, M. (2015). Life satisfaction and sexual minorities: Evidence from Australia and the United Kingdom. Journal of Economic Behavior \& Organization, 116, 107-126. doi:10.1016/j.jebo.2015.04.012

Priller, E., \& Schupp, J. (2011). Social and economic characteristics of financial and blood donors in Germany. DIW Economic Bulletin, 6, 23-30.

Pritchard, A., Richardson, M., Sheffield, D., \& McEwan, K. (2019). The relationship between nature connectedness and eudaimonic well-being: A meta-analysis. Journal of Happiness Studies. doi:10.1007/s10902-019-00118-6

Rad, M. S., Martingano, A. J., \& Ginges, J. (2018). Toward a psychology of Homo sapiens: Making psychological science more representative of the human population. Proceedings of the National Academy of Sciences, 115(45), 11401-11405. doi:10.1073/pnas.1721165115

Rand, D. G., Kraft-Todd, G., \& Gruber, J. (2015). The collective benefits of feeling good and letting go: Positive emotion and (dis)inhibition interact to predict cooperative behavior. PLoS ONE, 10(1), e0117426. https://doi.org/10.1371/journal.pone.0117426

Richards, M., \& Huppert, F. A. (2011). Do positive children become positive adults? Evidence from a longitudinal birth cohort study. The Journal of Positive Psychology, 6(1), 75-87. https://doi.org/10.1080/17439760.2011.536655

Ryan, R. M., \& Deci, E. L. (2000). Self-determination theory and the facilitation of intrinsic motivation, social development, and well-being. American Psychologist, 55, 68-78. https://doi.org/10.1037/0003066X.55.1.68

Ryan, R. M., \& Deci, E. L. (2001). On happiness and human potentials: A review of research on hedonic and eudaimonic well-being. Annual Review of Psychology, 52(1), 141-166. https://doi.org/10.1146/annurev.psych.52.1.141

Ryan, R. M., \& Huta, V. (2009). Wellness as healthy functioning or wellness as happiness: the importance of eudaimonic thinking (response to the Kashdan et al. and Waterman discussion). The Journal of Positive Psychology, 4, 202-204. https://doi.org/10.1080/17439760902844285

Ryff, C. D. (1995). Psychological well-being in adult life. Current Directions in Psychological Science, 4(4), 99-104. https://doi.org/10.1111/1467-8721.ep10772395

Ryff, C. D., \& Singer, B. (1998). The contours of positive human health. Psychological Inquiry, 9, 1-28. https://doi.org/10.1207/s15327965pli0901_1

Ryff, C. D., \& Singer, B. H. (2008). Know thyself and become what you are: A eudaimonic approach to psychological well-being. Journal of Happiness Studies, 9(1), 13-39. https://doi.org/10.1007/s10902-0069019-0

Santos, H. C., Varnum, M. E. W., \& Grossmann, I. (2017). Global increases in individualism. Psychological Science, 28(9), 1228-1239. doi:10.1177/0956797617700622

Seery, M. D., Holman, E. A., \& Silver, R. C. (2010). Whatever does not kill us: Cumulative lifetime adversity, 
vulnerability, and resilience. Journal of Personality and Social Psychology, 99, 1025-1041. https://doi.org/10.1037/a0021344

Sheldon, K. M., \& Lyubomirsky, S. (2004). Achieving sustainable new happiness: Prospects, practices, and prescriptions. In P. A. Linley \& S. Joseph (Eds.), Positive psychology in practice (pp. 127-145). Hoboken, NJ: Wiley. https://doi.org/10.1002/9780470939338.ch8

Sin, N. L. (2016). The protective role of positive wellbeing in cardiovascular disease: Review of current evidence, mechanisms, and clinical implications. Current Cardiology Reports, 11(18), 106. https://doi.org/10.1007/s11886-016-0792-z

Smith, J. L., \& Hollinger-Smith, L. (2015). Savoring, resilience, and psychological well-being in older adults. Aging \& Mental Health, 19, 192-200. doi:10.1080/1360863.2014.986647

Son, J., \& Wilson, J. (2012). Volunteer work and hedonic, eudemonic, and social wellbeing. Sociological Forum, 27(3), 658-681. https://doi.org/10.1111/j.1573-7861.2012.01340.x

Sone, T., Nakaya, N., Ohmori, K., Shimazu, T., Higashiguchi, M., Kakizaki, M., ... Tsuji, I. (2008). Sense of life worth living (ikigai) and mortality in Japan: Ohsaki study. Psychosomatic Medicine, 70, 709-715. https://doi.org/10.1097/PSY.0b013e31817e7e64

Southwick, S., \& Charney, D. (2018). Resilience: The science of mastering life's greatest challenges (2nd ed.). Cambridge, United Kingdom: Cambridge University Press. https://doi.org/10.1017/9781108349246

Stebbins, R. A. (2001). Serious leisure. Society, 38, 53-57. https://doi.org/10.1007/s12115-001-1023-8

Steger, M. F. (2009). Meaning in life. In S. J. Lopez (Ed.), Oxford Handbook of Positive Psychology (2nd ed.) (pp. 679-687). Oxford, UK: Oxford University Press. https://doi.org/10.1093/oxfordhb/9780195187243.013.0064

Steger, M. F. (2012). Experiencing meaning in life: Optimal functioning at the nexus if well-being, psychopathology, and spirituality. In P. T. P. Wong (Ed.), Human Quest for Meaning: Theories, Research, and Applications (pp. 165-184). Taylor \& Francis: Florence.

Stiglitz, J., Sen, A., \& Fitoussi, J.-P. (2009). The measurement of economic performance and social progress revisited. Commission on the Measurement of Economic Performance and Social Progress, Paris, France. Retrieved from http://www.ofce.sciences-po.fr/pdf/dtravail/WP2009-33.pdf

Suldo, S. M., Thalji, A., \& Ferron, J. (2011). Longitudinal academic outcomes predicted by early adolescents' subjective wellbeing, psychopathology, and mental health status yielded from a dual-factor model. Journal of Positive Psychology, 6(1), 17-30. https://doi.org/10.1080/17439760.2010.536774

Thoits, P. A., \& Hewitt, L. N. (2001). Volunteer work and wellbeing. Journal of Health and Social Behavior, 42, 115-131. https://doi.org/10.2307/3090173

Tugade, M. M., \& Fredrickson, B. L. (2004). Resilient individuals use positive emotions to bounce back from negative emotional experiences. Journal of Personality and Social Psychology, 86, 320-333. doi:10.1037/0022-3514.86.2.3202004-10747-009

Uchida, Y., \& Oishi, S. (2016). The happiness of individuals and the collective. Japanese Psychological Research, 58(1), 125-141. doi:10.1111/jpr.12103

Verkuyten, M. (2008). Life satisfaction among ethnic minorities: The role of discrimination and group identification. Social Indicators Research, 89(3), 391-404. https://doi.org/10.1007/s11205-008-9239-2

Verme, P. (2009). Happiness, freedom and control. Journal of Economic Behavior and Organization, 71, 146-161. https://doi.org/10.1016/j.jebo.2009.04.008

Walsh, L. C., Boehm, J. K., \& Lyubomirsky, S. (2018). Does happiness promote career success? Revisiting the evidence. Journal of Career Assessment, 26, 199-219. https://doi.org/10.1177/1069072717751441

Watson, D., Clark, L. A., \& Tellegen, A. (1988). Development and validation of brief measures of positive and negative affect: The PANAS scales. Journal of Personality and Social Psychology, 54(6), 1063-1070. https://doi.org/10.1037/0022-3514.54.6.1063

Weathers, L. N., Aiena, B. J., Blackwell, M. A., \& Schulenberg, S. E. (2016). The significance of meaning to conceptualizations of resilience and posttraumatic growth: Strengthening the foundation for research and practice. In P. Russo-Netzer, S. E. Schulenberg, \& A. Batthyany (Eds.), Clinical perspectives on meaning (pp. 149-169). Cham, Switzerland: Springer International Publishing. https://doi.org/10.1007/978-3-319-41397-6_8 
Welzel, C., \& Inglehart, R. (2010). Agency, values, and well-being: A human development model. Social Indicators Research, 97, 43-63. https://doi.org/10.1007/s11205-009-9557-z

Whitburn, J., Linklater, W., \& Abrahamse, W. (2019). Meta-analysis of human connection to nature and proenvironmental behavior. Conversation Biology, doi:10.1111/cobi.13381

Wiest, M., Schüz, B., Webster, N., \& Wurm, S. (2011). Subjective wellbeing and mortality revisited: Differential effects of cognitive and emotional facets of wellbeing on mortality. Health Psychology, 30(6), 728-735. https://doi.org/10.1037/a0023839

Williams, K. D. (2007). Ostracism. Annual Review of Psychology, 58, 425-452. https://doi.org/10.1146/annurev.psych.58.110405.085641

Wong, P. T. (2011). Positive psychology 2.0: Towards a balanced interactive model of the good life. Canadian Psychology/Psychologie Canadienne, 52(2), 69-81. https://doi.org/10.1037/a0022511

Yoo, H. C., Kim, A. Y., \& Lee, R. M. (2018). Race and subjective well-being: Critical race perspective and empirical review of key predictors. In E. Diener, S. Oishi, \& L. Tay (Eds.), Handbook of well-being. Salt Lake City, UT (USA): DEF Publishers. DOI:nobascholar.com

Zautra, A. J., Johnson, L. M., \& Davis, M. C. (2005). Positive affect as a source of resilience for women in chronic pain. Journal of Consulting and Clinical Psychology, 73, 212-220. https://doi.org/10.1037/0022006X.73.2.212 